\title{
Development of Wind-and-React Bi-2212 Accelerator Magnet Technology
}

\author{
A. Godeke, D. Cheng, D. R. Dietderich, C. D. English, H. Felice, C. R. Hannaford, S. O. Prestemon, G. Sabbi, \\ R. M. Scanlan, Y. Hikichi, J. Nishioka, and T. Hasegawa
}

\begin{abstract}
We report on the progress in our $R \& D$ program, targeted to develop the technology for the application of $\mathrm{Bi}_{2} \mathrm{Sr}_{2} \mathrm{CaCu}_{2} \mathrm{O}_{x}(\mathrm{Bi}-2212)$ in accelerator magnets. The program uses subscale coils, wound from insulated cables, to study suitable materials, heat treatment homogeneity, stability, and effects of magnetic field and thermal and electro-magnetic loads. We have addressed material and reaction related issues and report on the fabrication, heat treatment, and analysis of subscale $\mathrm{Bi}-2212$ coils. Such coils can carry a current on the order of $5000 \mathrm{~A}$ and generate, in various support structures, magnetic fields from $\mathbf{2 . 6}$ to 9.9 T. Successful coils are therefore targeted towards a hybrid $\mathrm{Nb}_{3} \mathrm{Sn}-\mathrm{HTS}$ magnet which will demonstrate the feasibility of Bi-2212 for accelerator magnets, and open a new magnetic field realm, beyond what is achievable with $\mathrm{Nb}_{3} \mathrm{Sn}$.
\end{abstract}

Index Terms-Accelerator magnet, High Temperature Superconductor, Wind-and-React, $\mathrm{Bi}_{2} \mathrm{Sr}_{2} \mathrm{CaCu}_{2} \mathrm{O}_{x}, \mathrm{Bi}-2212$

\section{INTRODUCTION}

$\mathbf{P}$ ROTOTYPE $\mathrm{Nb}_{3} \mathrm{Sn}$ accelerator-type superconducting dipole magnets have achieved steadily increasing magnetic fields. The present record of $16 \mathrm{~T}$ at $4.5 \mathrm{~K}$ [1], far surpasses the maximum achievable magnetic field of $10.5 \mathrm{~T}$ at $1.8 \mathrm{~K}$ for NbTi magnets [2]. It can be shown, however, that $\mathrm{Nb}_{3}$ Sn-based dipole magnets are limited to 17 to $18 \mathrm{~T}$ [3]. A switch to a new material with a higher magnetic field limit is therefore inevitable to approach magnetic fields of $20 \mathrm{~T}$.

$\mathrm{Bi}-2212$ is available in round wire (a key requirement for accelerator-type magnets), has an engineering current density that surpasses $\mathrm{Nb}_{3} \mathrm{Sn}$ at about $18 \mathrm{~T}$ [4], and an effective upper critical magnetic field of about $85 \mathrm{~T}$ [5], yielding a current density that depends only marginal on the magnetic field above $5 \mathrm{~T}$. Bi-2212 is therefore ideal for increasing the magnetic field in hybrid systems. We believe that a Wind-and-React (W\&R) process is the only feasible method to manufacture very high field magnets with $\mathrm{Bi}-2212$, due to the material's irreversible loss of critical current with strain [3]. The practical implementation of $\mathrm{Bi}-2212$ is further complicated by the its chemical activity during the heat treatment, and the requirement for a reaction at about $890 \pm 2^{\circ} \mathrm{C}$ in pure Oxygen

Manuscript received August 28, 2007. This work was supported by the Director, Office of Science, High Energy Physics, U.S. Department of Energy under contract No. DE-AC02-05CH11231.

A. Godeke (corresponding author; phone: +1-510-486-4356; e-mail: agodeke@1bl.gov), D. Cheng, D. R. Dietderich, C. D. English, H. Felice, C. R. Hannaford, S. O. Prestemon, G. Sabbi, and R. M. Scanlan are with Lawrence Berkeley National Laboratory, One Cyclotron Rd, Berkeley CA 94720, USA.

Y. Hikichi, J. Nishioka, and T. Hasegawa are with SWCC Showa Cable Systems Co., Ltd., 4-1-1 Minami-Hashimoto, Sagamihara, Kanagawa, 2291133, Japan

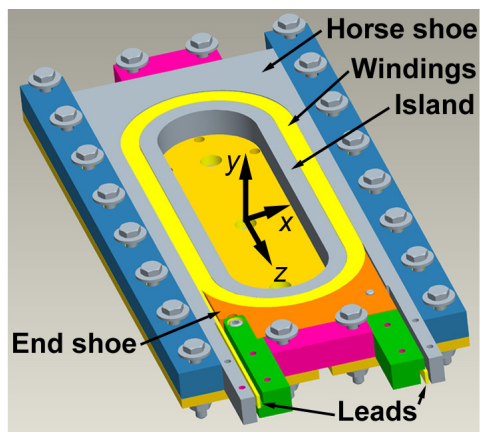

Fig. 1. Schematic representation of a $2 \times 6$ turn subscale $\mathrm{Bi}-2212$ magnet.

for W\&R coil manufacture. This article reports our findings on insulation and construction material compatibility, initial assessments on quench protection issues, coil manufacture, heat treatment optimizations, and initial subscale coil results.

\section{BI-2212 SUBSCALE MAGNET PROGRAM}

The development of accelerator-type $\mathrm{Bi}-2212$ magnets is based on LBNL's $\mathrm{Nb}_{3} \mathrm{Sn}$ subscale magnet program [6] (Figure 1). In this way, the program can take advantage of the existing infrastructure, which includes various mechanical structures for subscale coil testing. $\mathrm{Nb}_{3} \mathrm{Sn}$ subscale coils are usually two layer, $2 \times 20$ turns racetrack coils. The number of turns has been reduced to $2 \times 6$ turns in the initial development stage of the $\mathrm{Bi}-2212$ program, and will be increased once the partial melt heat treatment of the coils is sufficiently developed.

Simulations were performed to estimate the achievable magnetic fields and loads on the $\mathrm{Bi}-2212$ winding pack. The simulations assume a measured strand critical current of $400 \mathrm{~A}$ in self-field at $4.2 \mathrm{~K}$, and a Bi-2212-typical dependence of the critical current on magnetic field [5]. Table I presents an overview of the results of these simulations for stand-alone $\mathrm{Bi}$ 2212 coils, a common coil $\mathrm{Bi}-2212$ system with a $4 \mathrm{~mm}$ gap between the two coils and the current in opposite directions, a dipole configuration with a $4 \mathrm{~mm}$ gap and current in the same direction, and two hybrid systems comprising a Bi-2212 coil between two $\mathrm{Nb}_{3} \mathrm{Sn}$ coils. The coils are supported by existing mechanical structures in the common coil, dipole and hybrid configurations. The magnetic field $\left(\mu_{0} H\right)$ listed in Table I represents the maximum field in the $\mathrm{Bi}-2212$ windings. The depicted pressures $\left(P_{x-z}\right.$, directions as sketched in Figure 1) are obtained through a simple area division of the Lorentz 
TABLE I

WIND-AND-REACT BI-2212 SUBSCALE COIL TEST CONFIGURATIONS

\begin{tabular}{|c|c|c|c|c|c|c|c|}
\hline Layout & Turns & $\mu_{0} H[\mathrm{~T}]$ & $I_{s s}[\mathrm{~A}]$ & $L[\mathrm{mH}]$ & $P_{x}[\mathrm{MPa}]$ & $P_{y}[\mathrm{MPa}]$ & $P_{z}[\mathrm{MPa}]$ \\
\hline $\mathrm{Bi}-2212$ stand alone & $2 \times 6$ & 2.6 & 6213 & 0.036 & 1.1 & 0 & 1.9 \\
\hline $\mathrm{Bi}-2212$ stand alone & $2 \times 19$ & 4.9 & 5179 & 0.25 & 9.7 & 0 & 9.4 \\
\hline Bi-2212 common coil ${ }^{\mathrm{a}}$ & $2 \times 19$ & 5.8 & 4948 & 0.28 & 27 & 7.5 & 15 \\
\hline Bi-2212 dipole ${ }^{a}$ & $2 \times 19$ & 6.6 & 4777 & 1.2 & 1.6 & 14 & 3.2 \\
\hline $1 \times \mathrm{Bi}-2212 / 2 \times \mathrm{Nb}_{3} \mathrm{Sn}$ hybrid dipole ${ }^{\mathrm{ab}}$ & $\begin{array}{c}2 \times 19(\mathrm{Bi}-2212) \\
2 \times 20\left(\times 2 \quad \mathrm{Nb}_{3} \mathrm{Sn}\right)\end{array}$ & 8.5 & 4595 & 2.4 & 34 & 0 & 20 \\
\hline $1 \times \mathrm{Bi}-2212 / 2 \times \mathrm{Nb}_{3} \mathrm{Sn}$ hybrid dipole ${ }^{\mathrm{ac}}$ & $\begin{array}{c}2 \times 19(\mathrm{Bi}-2212) \\
2 \times 20\left(\times 2 \quad \mathrm{Nb}_{3} \mathrm{Sn}\right)\end{array}$ & 9.9 & $\begin{array}{c}4486(\mathrm{Bi}-2212) \\
6112\left(\mathrm{Nb}_{3} \mathrm{Sn}\right)\end{array}$ & & & & \\
\hline
\end{tabular}

${ }^{a}$ With an iron insert inside the $\mathrm{Bi}-2212$ subscale island

b $\mathrm{Bi}-2212$ and $\mathrm{Nb}_{3} \mathrm{Sn}$ in series connected and Bi-2212 limited

c $\mathrm{Bi}-2212$ and $\mathrm{Nb}_{3} \mathrm{Sn}$ driven independently

force. Experience with subscale coil simulations suggests that this roughly compares to the maximum pressure on the cable.

Table I shows a typical scheme to test $\mathrm{Bi}-2212$ coils in order of increasing magnetic field and load on the cable. The latter is preferred since research on the sensitivity of $\mathrm{Bi}-2212$ to axial strain [3] and transverse pressure [7] indicates a significant irreversible axial strain dependence of the critical current and a maximum allowable transverse load of 60 and $100 \mathrm{MPa}$ on the face and edge orientations, respectively. The simulations indicate that the loads stay well within these limits, even in a hybrid structure approaching a magnetic field of $10 \mathrm{~T}$.

\section{MATERIALS SELECTION}

The materials to be used in $\mathrm{Bi}-2212$ coil manufacture have to fulfill three requirements: 1) They have to be able to withstand a heat treatment at about $890^{\circ} \mathrm{C}$ in pure $\mathrm{O}_{2}, 2$ ) They have to be chemically compatible during the partial melt heat treatment if they are in contact with the Ag-alloy matrix of the Bi-2212 cable [8], and 3) Their thermal expansion and contraction have to be compatible with that of the winding pack.

We initially selected pure $\mathrm{SiO}_{2}$ fiber sleeve as cable insulation, since separate compatibility tests on cables were promising. Coil tests, however, indicated that pure $\mathrm{SiO}_{2}$ is too sensitive to contaminations, resulting in the formation of glass phases that react with the Ag-alloy matrix, as was suggested earlier [8], [9]. $\mathrm{Al}_{2} \mathrm{O}_{3} / \mathrm{SiO}_{2} 72 \% / 28 \%$ mullite braided sleeve was identified as a better alternative. This sleeve insulation is manufactured with a wall thickness of $80 \mu \mathrm{m}$.

The sleeve arrives from the manufacturer with an organic sizing with an unknown, proprietary composition. This creates an uncertainty in the materials that are present in the coil windings during the heat treatment. In the initial coils we removed the sizing after coil winding, but before the reaction. Possible remaining sizing can, however, consume a significant amount of Oxygen during the reaction. This in turn can cause an Oxygen deficiency in the coil, which could potentially lower the Bi-2212 melt temperature. In the later coils we therefore removed the sizing before insulating the cable, initially at $600^{\circ} \mathrm{C}$ in air, and later at $825^{\circ} \mathrm{C}$ in pure $\mathrm{O}_{2}$ for 4 hours. The $\mathrm{Al}_{2} \mathrm{O}_{3} / \mathrm{SiO}_{2}$ mullite sleeve remains intact without the sizing even after significant handling, in contrast to our experience with $\mathrm{S}$-glass that is used to insulate $\mathrm{Nb}_{3} \mathrm{Sn}$ cables.
This means that the developed ceramic sleeve is also a very suitable insulation for $\mathrm{Nb}_{3} \mathrm{Sn}$ cables. The absence of sizing overcomes the carbon deposits that are often found inside a $\mathrm{Nb}_{3} \mathrm{Sn}$ magnet after reaction, as a result of the presence of organic sizing in the coils.

We continued to use Alloy 600 for structural coil parts as shown in Figure 2, since this provides the preferred match to the thermal contraction of the Bi-2212 [3]. We use Alloy C-276 for all bolts, except Stainless Steel 316L for bolts that are in the Oxygen flow path during the reaction. In addition, we are investigating the possibility to place $\mathrm{Zr}-702$ alloy and plasma sprayed $\mathrm{ZrO}_{2}$ in between the coil construction material and the winding pack. We consider this to prevent any chance of contact between the coil construction material and the winding pack and to provide a base-plane insulation. Separate tests using insulated cable sections sandwiched between $\mathrm{Zr}$ 702 strips showed that Zr-702 alloy forms a rigid, insulating oxide during the partial melt reaction that appears chemically compatible and able to withstand significant bending of the $\mathrm{Zr}-702$ strip. Compatibility tests of plasma sprayed $\mathrm{ZrO}_{2}$ are being preformed at the time of writing and we will continue to investigate other material options.

\section{PRELIMINARY QUENCH ANALYSIS}

Quench propagation measurements on $\mathrm{Bi}-2212$ are extensively described in the literature. The general conclusion is that a normal zone propagates only at a few $\mathrm{cm} / \mathrm{s}$, whereas in $\mathrm{Nb}_{3} \mathrm{Sn}$ a few tens of $\mathrm{m} / \mathrm{s}$ is common. It is therefore generally thought that $\mathrm{Bi}-2212$ magnet protection will be severely hindered by such a low quench propagation velocity.

However, most experiments in the literature are performed on very short samples with no external applied magnetic field at $4.2 \mathrm{~K}$ (where the zero field temperature margin is about $85 \mathrm{~K}$ ), or at $77 \mathrm{~K}$ (where the temperature margin is sufficiently low, but the heat capacity is roughly 1000 times larger than at $4.2 \mathrm{~K}$ ). In both cases a local hot spot will obviously not rapidly propagate. It is fortunate, however, that the effective phase boundary in $\mathrm{Bi}-2212$ is significantly lowered in the presence of a magnetic field. This lowering is usually attributed to thermal de-pinning of vortices. A practical implication is that, for example at a magnetic field of $10 \mathrm{~T}$, the effective temperature margin is reduced to about $20 \mathrm{~K}$, as can be seen from transport measurements [10]. 


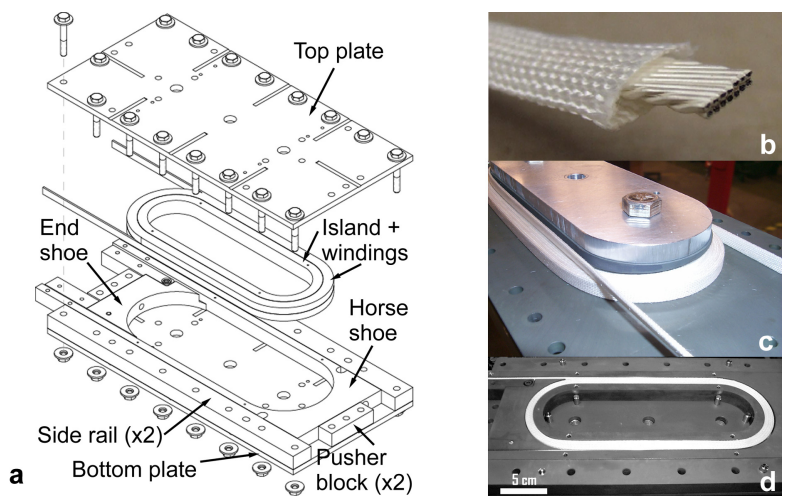

Fig. 2. a) Design of a 6 turn, 2 layer $\mathrm{Bi}-2212$ subscale coil in its reaction holder; b) Insulated Bi-2212 cable; c) Subscale coil winding; d) Subscale coil in reaction holder.

A reduced effective temperature margin in the presence of a magnetic field means that, pending accurate analysis of the thermodynamics of such systems, normal zone development might be more favorable than expected on the basis of measurements without an externally applied magnetic field. Quench development experiments will have to be performed on long samples in the presence of a significant background magnetic field to determine whether this reasoning is indeed correct. Such measurements have to be combined with an accurate characterization of the critical current as function of magnetic field and temperature, and with simulations of quench development in Bi-2212 coils. It should be noted that results on quench propagations in small solenoid coils at $8 \mathrm{~T}$ and $4.2 \mathrm{~K}$, report a normal zone propagation velocity of 0.5 to $4 \mathrm{cms}^{-2}$ [11] and therefore contradict the reasoning above.

Preliminary simulations were performed at LBNL to assess the risks involved in the tests of subscale $\mathrm{Bi}-2212$ coils at $4.2 \mathrm{~K}$ in low magnetic fields. These simulations assume that sufficient heat is deposited into a small, local volume of superconductor to evoke a quench. Results at $90 \%$ of the critical current show that for a hot-spot temperature of $100 \mathrm{~K}$, the coil voltage has risen to $35 \mathrm{mV}$ after $300 \mathrm{~ms}$, which appears detectable. The voltage then rises to $1 \mathrm{~V}$ at $375 \mathrm{~ms}$, so a common passive diode protection system incorporating an optimized resistance and set to trigger at about $1 \mathrm{~V}$ would result in a hot-spot temperature only marginally above $150 \mathrm{~K}$. A passive protection system is highly desirable at this phase of coil development.

\section{Subscale coil manufacture}

Two dummy subscale coils, and three Bi-2212 subscale coils have been manufactured at LBNL so far (Table II). Subscale, 17 strand $\mathrm{Bi}-2212$ cables are made from unreacted strand at $\mathrm{LBNL}$. $\mathrm{Al}_{2} \mathrm{O}_{3} / \mathrm{SiO}_{2}$ mullite sleeve, as received from the vendor, is heat cleaned to remove the sizing and placed around the cables (Figure 2). Coil parts were UHV cleaned and pre-oxidized for the initial coils. We are presently testing parts that are only UHV cleaned. Coils are wound around the island on the bottom plate of the reaction holder. After coil winding, the horse shoe and end shoe are placed. They are held in place with side rails, end blocks, and a top plate
TABLE II

WIND-AND-REACT BI-2212 SUBSCALE COILS

\begin{tabular}{lccc}
\hline \hline Coil ID & Cable & Insulation & Sizing \\
\hline HTS-SC01 & Ag-alloy dummy & Pure $\mathrm{SiO}_{2}$ & Present \\
HTS-SC02 & Ag dummy & Pure $\mathrm{SiO}_{2}$ & Present \\
HTS-SC03 & Untwisted Showa strand & $\mathrm{Al}_{2} \mathrm{O}_{3} / \mathrm{SiO}_{2}$ & Present \\
HTS-SC04 & Untwisted OST strand & $\mathrm{Al}_{2} \mathrm{O}_{3} / \mathrm{SiO}_{2}$ & Present \\
HTS-SC05 & Twisted Showa strand & $\mathrm{Al}_{2} \mathrm{O}_{3} / \mathrm{SiO}_{2}$ & $600^{\circ} \mathrm{C} / 1 \mathrm{~h}^{*}$ \\
\hline \hline
\end{tabular}

* Sizing removal reaction on insulation prior to insulating the cable

\begin{tabular}{|c|c|c|}
\hline$\frac{\bullet}{\text { Lead }}$ & $\begin{array}{l}\text { - Horse shoe } 1 \\
\text { - Cable } 1 \\
\text { - Island } 1\end{array}$ & - Cable 2 \\
\hline & - Cable 3 & $\begin{array}{l}\text { - Island } 2 \\
\text { : Cable } 4 \\
\text { - Horse shoe } 2\end{array}$ \\
\hline
\end{tabular}

Fig. 3. Thermocouple positions on the coil reaction package for heat treatment homogeneity tests at Showa on dummy subscale coil HTS-SC01.

which closes the reaction package. An Oxygen flow path is included in the design. Oxygen is forced through the island center, via slits in the top plate to the winding pack, through the winding pack, and then to the environment through slits in the bottom plate. Coil winding and all handling is performed in clean environments using non-talc gloves to prevent any undesired contamination of the reaction package. Finished coil assemblies are shipped to Showa for the heat treatment.

\section{PARTial MELT REACTION HEAT TREATMENT}

The reaction packages are equipped with a large number of thermocouples to monitor the temperature homogeneity during the partial melt heat treatment. The dummy coils HTS-SC01 and HTS-SC02 are used to optimize heat treatments. Figure 3 depicts the thermocouple positions on the reaction package of HTS-SC01 at Showa. Thermocouples are placed in the island, in the horse shoe, as well as at various other positions on the package and inside the oven. Thermocouples are also placed in holes in the windings of the dummy coils to measure the temperature of the cable. Since all registered temperatures during the heat treatments are within $\pm 1^{\circ} \mathrm{C}$ it is concluded that sufficient homogeneity can be achieved in reasonable sized coils.

The reaction time and temperature were optimized at Showa by removing one turn of the dummy windings and replacing it by a straight, insulated wire. Additional insulated straight wires were placed on top of the reaction package. The partial melt temperature and time were optimized for maximum current in the straight wires at $4.2 \mathrm{~K}$ in self-field. The optimized wire critical current is about $400 \mathrm{~A}$ and similar for wires inside and outside the dummy reaction package. One additional turn was then removed from the dummy winding pack, and a short (about $70 \mathrm{~cm}$ ) insulated cable section was placed inside the package. The critical current of this cable section was measured on 5 equidistant sections, yielding $381 \pm 6$ A at $64 \mathrm{~K}$ in self-field, confirming homogeneity of the cable and the heat treatment. Cable critical current measurements at $64 \mathrm{~K}$ 
roughly represent the strand current at $4.2 \mathrm{~K}$ and are used to judge the quality of the heat treatment.

Coils HTS-SC03 and HTS-SC05 were heat treated using the reaction as optimized for the wires and cable inside the dummy reaction package. Insulated cable sections were heat treated outside the reaction package together with the coils, to provide witness samples for the heat treatment. The cable section that was reacted together with HTS-SC03 measures $381 \mathrm{~A}$ at $64 \mathrm{~K}$ in self-field. The cable section that was reacted together with HTS-SC05 measures $264 \mathrm{~A}$ at $64 \mathrm{~K}$ in selffield. The lower value of the latter is attributed to the use of twisted strand in the cable. Twisting of the strand reduces the achievable critical current by about $20 \%$.

\section{BI-2212 COIL ANALYSIS}

Both HTS-SC03 and HTS-SC05 showed significant leakage after the partial melt reaction. Leakage occurred mainly at the cable edges in the winding pack and was nearly absent at the leads. Energy Dispersive X-ray chemical analysis on the insulation where leakage occurred, identified mainly $\mathrm{Cu}$ and $\mathrm{Sr}$, as well as some traces of $\mathrm{Ca}$ and $\mathrm{Bi}$.

SEM cross-sections of cables inside HTS-SC03 identified a higher degree of deformation at the cable edges compared to a cable that was reacted without any confinement. The cable thickness of a free reacted cable increases by at least $5 \%$ compared to an unreacted cable. This cable growth during the heat treatment, as well as the larger expansion of the Agalloy matrix in comparison to the Alloy 600 coil former, are presently not accounted for, and believed to be a main cause for the observed leakage. Confinement of the windings is, in addition to possible mechanical effects, also of influence on the Oxygen content within the windings. Oxygen shortage could therefore be a second cause for the observed leakage.

A separate test was designed to investigate the effect of confinement on a single cable (Figure 4). In this test one insulated cable is enclosed in an Alloy 600 package and heat treated together with a witness cable on top of the package. The confinement is adjusted with shims to approximately represent the confinement in HTS-SC03. The free cable does not show any signs of leakage. The confined cable clearly exhibits leakage, though not as severe as was observed in the coils. These results confirm that cable confinement is a cause for leakage, but further investigations are needed to be conclusive between mechanical and Oxygen flow effects.

A set of three coils, designed to provide various degrees of freedom to the winding pack, are presently under construction to address the cable expansion and Oxygen flow issues. Chemical incompatibility is presently not suspected to be the prime source of leakage, since unconfined cables, the cable section that was heat treated in the dummy coil package, and the leads, do not exhibit leakage.

\section{CONCLUSION}

Development of $\mathrm{Bi}-2212$ accelerator magnet technology is progressing and five subscale coils were manufactured. Some developments, specifically with respect to chemical compatibility, proved difficult but solvable. Heat treatment homogeneity and quench protection issues appear less problematic

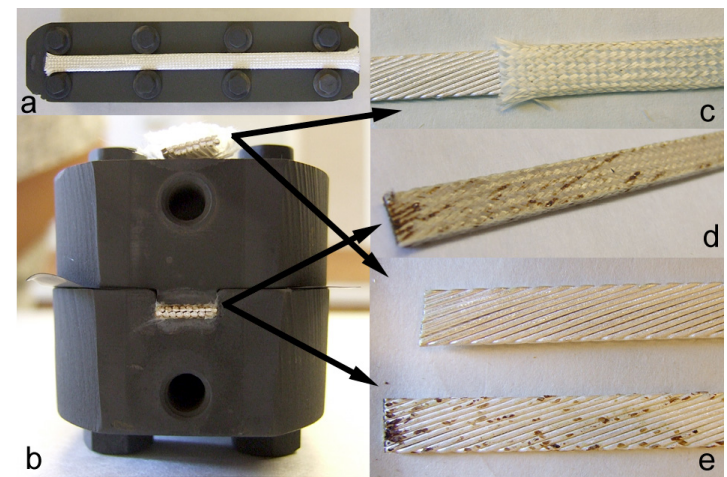

Fig. 4. a) Alloy 600 confinement test package (top) and b) front view. c) Free heat treated cable with insulation partly removed. d) Confined heat treated cable with insulation. e) Free (top) and confined (bottom) heat treated cables with insulation removed.

than initially expected. Though coils that exhibit leakage are superconducting and in principle usable, it has to be avoided. We will modify our processes to create an improved balance between the cable and reaction package dimensional changes. In parallel, we will develop an optimized Oxygen flow. We therefore expect that the observed leakage problem can be solved.

\section{ACKNOWLEDGMENT}

The authors would like to thank P. Bish, H. C. Higley, D. Horler, N. L. Liggins, G. Ritchie, and J. Swanson for their technical expertise, M. Alessandrini for quench propagation studies, and J. N. Giddings, K. Tsao, and L. Sun for their help with heat treatment compatibility studies and SEM and EDX analysis.

\section{REFERENCES}

[1] A. F. Lietzke et al., "Test results for HD1, a 16 Tesla $\mathrm{Nb}_{3} \mathrm{Sn}$ dipole magnet," IEEE Trans. Appl. Supercond., vol. 14, no. 2, p. 345, 2004.

[2] D. Leroy et al., "Design Futures and Performance of a $10 \mathrm{~T}$ Twin Aperture Model Dipole for LHC," in Proc. of the $15^{\text {th }}$ International Conference on Magnet Technology, Beijing, China, L. Lianghzhen, S. Guoliao, and Y. Lugang, Eds., vol. 1. Science Press, Beijing, China, 1998 , p. 119.

[3] A. Godeke et al., "Limits of $\mathrm{NbTi}$ and $\mathrm{Nb}_{3} \mathrm{Sn}$, and development of W\&R Bi-2212 high field accelerator magnets," IEEE Trans. Appl. Supercond., vol. 17 , no. 2 , p. $1149,2007$.

[4] K. Marken et al., "Progress in Bi-2212 wire and coils for superconducting magnets," Presented at the MRS Spring Meeting, San Francisco, CA, USA, April 19, 2006

[5] U. P. Trociewitz et al., "Bi2212 superconductors in high field applications," NHMFL Reports 2006, vol. 13, no. 1, p. 31, 2006.

[6] R. R. Hafalia et al., "An approach for faster high field magnet technology development," IEEE Trans. Appl. Supercond., vol. 13, no. 2, p. 1258, 2003.

[7] D. R. Dietderich et al., "Critical current variation as a function of transverse stress on Bi-2212 Rutherford cables," IEEE Trans. Appl. Supercond., vol. 11, no. 1, p. 3577, 2001.

[8] D. E. Wesolowski et al., "Reactions between oxides and Ag-sheathed $\mathrm{Bi}_{2} \mathrm{Sr}_{2} \mathrm{CaCu}_{2} \mathrm{O}_{x}$ conductors," Supercond. Sci. and Techn., vol. 18, p. 934, 2005.

[9] E. E. Hellstrom, Private communication, 2006

[10] V. R. Romanovskii, S. Awaji, G. Nishijima, and K. Watanabe, "Suband overcritical stable states of composite high- $T_{c}$ superconductors with different $E(J)$ dependences and their unavoidable overheating," J. Appl. Phys., vol. 100, p. 063905, 2006.

[11] U. P. Trociewitz et al., "Quench studies on $\mathrm{Bi}_{2} \mathrm{Sr}_{2} \mathrm{CaCu}_{2} \mathrm{O}_{x}$ coils," Presented at the 2006 Appl. Supercond. Conf., Seattle, WA, USA. 